\title{
A PRODUÇÃO ESCRITA NO ENSINO FUNDAMENTAL I: CORREÇÃO DO PROFESSOR E REVISÃO DO TEXTO PELO ALUNO
}

\author{
LA PRODUCCIÓN ESCRITA EN LA ENSEÑANZA PRIMARIA: CORRECCIÓN DEL PROFESOR Y REVISIÓN \\ DEL TEXTO POR EL ALUMNO
}

\section{WRITING PRODUCTION IN ELEMENTARY SCHOOL: CORRECTION OF THE TEXT BY TEACHER AND REVIEW BY THE STUDENT}

\author{
Jennifer Galvão Cezar* \\ Orlando de Paula \\ Universidade de Taubaté - UNITAU
}

\begin{abstract}
RESUMO: Este artigo apresenta um estudo do ensino da produção escrita no contexto escolar, enfocando a revisão do texto pelo aluno a partir da avaliação do professor. Procuramos responder às perguntas: De que forma o professor tem realizado as devolutivas das redações corrigidas ao aluno? O que nos dizem os estudiosos da área quanto aos processos de correção do texto escrito do aluno? Para tanto, numa perspectiva interacionista, recorremos aos autores que orientam o ensino por meio dos gêneros para uma prática de produção escrita do ponto de vista dialógico. Acreditamos que, somente considerando tais aspectos, o professor poderá realizar sua devolutiva ao aluno, ampliando sua visão sobre a produção escrita e recriando diferentes estratégias de correção. Sendo assim, este trabalho sugere possibilidades de correção no contexto escolar, voltados para o público dos $4^{\circ}$ e $5^{\circ}$ anos do Ensino Fundamental I.
\end{abstract}

PALAVRAS-CHAVE: produção textual escrita; ensino fundamental; correção; gêneros.

RESUMEN: Este artículo presenta un estudio de la enseñanza de la escritura en el contexto escolar, focalizando la revisión del texto por el alumno a partir de la evaluación del profesor. Buscamos contestar a las preguntas: ¿De qué manera el profesor ha hecho las redacciones retroalimentar al estudiante? ¿Qué nos dicen los estudiosos del asunto cuanto a los procesos de corrección de escritura del alumno? Para eso, en una perspectiva interaccionista, recurrimos a los autores que orientan la enseñanza a través de los géneros para una práctica de producción escrita del punto de vista dialógico. Creemos que, solamente considerando tales aspectos, el profesor, al devolver corregida la escritura del alumno, podrá ampliar su visión sobre la producción escrita y recrear distintas estrategias de corrección. En ese sentido, este trabajo sugiere posibilidades de corrección en el contexto escolar, volviéndonos al público de los $4^{\circ}$ y $5^{\circ}$ años de la Escuela Primaria I.

PALABRAS-CLAVE: producción textual escrita; enseñanza primaria; corrección; géneros.

ABSTRACT: This article presents a study on writing production teaching in the school context, focusing on the text revision by the student after the teacher's assessment. We try to answer the questions: how has the teacher held the feedback of the text correction to the student? What do the authors tell us about the area regarding evaluation processes of the student's written text correction? Apart from an interaccionist perspective, we turn to the authors that guide teaching through genres for a practice of writing production based on a dialogic perspective. We believe that only considering such aspects, the teacher can perform their feedback to students, expanding their vision about the writing production and recreating different correction strategies. Thus, this work suggests correction possibilities in the school context for students in the 4th and 5th grades in elementary school.

KEYWORDS: textual writing production; elementary school; correction; genres.

\section{INTRODUÇÃO}

Atualmente, temos assistido a um grande esforço para unir os resultados de pesquisas sobre o ensino de produção textual escrita na educação básica à prática desse ensino na sala de aula. Observamos que as habilidades básicas de leitura e escrita não têm sido potencializadas pelos alunos, conforme dados evidenciados e divulgados em avaliações dos alunos da educação básica por meio da Prova Brasil, que integra o sistema de Avaliação da Educação Básica (SAEB) e o Exame Nacional do Ensino Médio (ENEM). Podemos dizer que, por se relegar o desenvolvimento de tais habilidades ao segundo plano, os alunos demonstram dificuldades na compreensão e produção de textos. 
Em se tratando do ensino da leitura e escrita, Antunes (2009), Geraldi (2007), Bunzen (2006), Lopes-Rossi (2002, 2006, 2012) e Passarelli (2004) recomendam que o ensino da produção textual seja feito a partir do ensino dos gêneros ${ }^{1}$.

Notamos, de acordo com nossa experiência docente, que essa recomendação começa a ser incorporada à prática pedagógica, ainda que de forma incipiente por parte dos educadores, como se verifica em Soares (apud COSTA, 2008). A autora afirma que existem, por parte do professor, muitas dúvidas relativas à nova teoria, mas, apesar delas, algumas tentativas de ajustar o trabalho às novas recomendações teóricas estão sendo feitas, mesmo com lacunas. Contudo, cabe ressaltar que poucos são os referenciais que abordam a temática das revisões textuais praticadas pelo professor e da devolutiva dessa correção, pelo professor, ao aluno. Por isso, questionamo-nos se, após produzir um texto, os alunos têm recebido alguma devolutiva do professor, e, se isso tem se efetivado, de que maneira têm sido feitas tais devolutivas. Além disso, buscamos conhecer o que nos orientam os referenciais teóricos acerca dessa devolutiva.

Em resposta a essas indagações, procuramos, neste estudo, refletir sobre parte importante, senão essencial, do processo de ensino da produção textual escrita: a correção e a devolutiva da produção escrita ao aluno. Procuramos refletir com base nas seguintes questões: De que forma o professor tem realizado as devolutivas dos textos corrigidos? O que nos dizem os estudiosos da área quanto aos processos de avaliação/correção do texto escrito do aluno?

Com vistas a esse propósito, inicialmente, apresentaremos um panorama das correntes práticas em sala de aula, explicitando o tratamento que se tem dado à correção da produção escrita dos alunos e o modo como estes a percebem. Em seguida, é retomada a noção de gêneros e o processo de correção e revisão do texto escrito. Discutem-se algumas questões terminológicas acerca das denominações "correção", "erro", "redação", apresentando, em seguida, algumas estratégias de correção utilizada por alguns professores a partir de uma pesquisa feita por Ruiz (2010) ao retomar Serafini (1998). Para finalizar, e diante da escassez de materiais voltados para o processo de intervenção no texto escrito de alunos do Ensino Fundamental I (doravante, EF I), interpretamos, com as devidas adaptações, as estratégias apresentadas na literatura pertinente ao ensino da produção textual no Ensino Fundamental II (doravante, EF II). À luz dessas orientações, e com base em nossa experiência docente, adaptamos uma proposta para ser utilizada com os alunos dos $4^{\circ}$ e $5^{\circ}$ anos do EF I. Com isso, tecemos nossas considerações com vista aos processos interventivos que são ou não realizados nesse nível de ensino da educação básica, fase em que os alunos, podemos dizer, já estão alfabetizados e possuem condições de iniciar a atividade de produção textual.

\section{O ENSINO DA PRODUÇÃo TEXTUAL ESCRITA: O CENÁRIO}

De modo geral, pode-se dizer que a avaliação da produção do texto escrito obedece a certa tendência subjetiva, pois muitos professores avaliam as produções escritas dos alunos como boas ou ruins sem ter, contudo, estabelecido critérios claros para essa avaliação. Por isso, torna-se uma tarefa difícil explicitar aos alunos por que o texto de um está bom e o texto de outro não. Como os critérios não ficam claros, as justificativas aos alunos, geralmente, recaem sobre problemas gramaticais.

Outro fator a considerar é a questão do dom da escrita. Difunde-se em ambiente escolar a concepção de que escrever é um dom para poucos. Passarelli (2004,) trata a questão sob a chamada aura mítica discorrendo, a partir de Krashen, que os estudantes têm a noção de que devem colocar as ideias no papel de uma só vez, do início ao fim, sem qualquer pausa ou planejamento, revisão ou reescrita. Sendo assim, demonstram que não percebem a produção escrita como atividade processual. Essa visão dos estudantes corresponde ao tratamento que a escola tem dado às suas produções. Normalmente, centrada no produto final, pois, para ela, importa se o texto do aluno não está poluído por erros ortográficos ou gramaticais. Espera-se um produto perfeito, pois o enfoque dos olhares está nos aspectos normativos (BUNZEN, 2006; PASSARELLI, 2004).

\footnotetext{
1 A questão terminológica acerca da pertinência da expressão "gêneros textuais" ou "gêneros discursivos", "tipos textuais" ou “tipos discursivos" ainda não é consenso entre os pesquisadores. Alguns omitem a adjetivação trabalhando apenas com o termo gênero, outros, optam por gênero textual por observar que "gêneros são formas textuais" (PASSARELLI, 2008a, p. 118). Já se viu o emprego de "gêneros discursivos" (BAKHTIN, 2003) porque assim são encontrados nos referenciais bakhtinianos (LOPES-ROSSI, 2002) e outros, ainda, optam por uma delas, tomando-as como expressões intercambiáveis, salvo quando é preciso a identificação de um fenômeno específico (MARCUSCHI, 2008, p.154). Neste artigo, utilizaremos, na maior parte, a expressão gêneros para nos referirmos aos gêneros textuais/discursivos, salvo nas citações dos autores, para respeitar a expressão que adotam.
} 
Passarelli (2004, p. 27) revela-nos a noção de que a escola, até então, guardou para si um segredo: "bons escritores planejam e revisam, além de produzirem muitos rascunhos ou esboços." Por isso, é fundamental que os professores desenvolvam seu trabalho sob a perspectiva processual para que os alunos não vejam a primeira escritura como etapa final, mas como uma primeira versão que pode e deve ser revista e aperfeiçoada.

Nas produções escritas, de acordo com Geraldi (2007), os temas são repetidos ano após ano, de forma desagregada do real sentido da língua, sendo o professor o único leitor da produção e, geralmente, leitor para fins avaliativos. Passarelli (2004) acrescenta que os alunos são levados a redigir sobre temas determinados pelo professor e a partir das técnicas básicas de redação, apoiadas na tipologia de textos: narração, descrição e dissertação. Para Antunes (2006, p. 25-27), o que existe nas salas de aula é:

i) uma prática mecânica de escrita, em que se prioriza escrever sem erros de ortografia;

ii) uma prática em que não se percebe o valor interacional da linguagem; escreve-se para ser avaliado, para exercitar, sendo, portanto, um texto sem identidade, pois não tem autoria, nem recepção;

iii) uma prática de escrita improvisada, sem planejamento, sem revisão, não importando o seu conteúdo, nem modo de realização, pois a necessidade é que se cumpra tal dever.

Verifica-se, assim, que o tratamento comumente dado às produções textuais restringe-se aos professores que as corrigem - priorizando perspectivas da superfície textual -, dão nota e entregam a seus alunos que, por sua vez, guardam de recordação ou delas se desfazem. Dessa forma, a visão processual de escrita inexiste na prática de boa parte do professorado, não havendo espaço para a revisão do texto, nem para a devolutiva ao aluno.

Geraldi (2007, p.40-41) aponta-nos que as ações que se relacionam à sala de aula dependem de uma interpretação da realidade, ou seja, às ações subjaz uma concepção de linguagem. Para o autor, “[ [...] os conteúdos ensinados, o enfoque que se dá a eles, as estratégias de trabalho com os alunos, a bibliografia utilizada, o sistema de avaliação, o relacionamento com os alunos [...]”, tudo depende do caminho pelo qual optamos. O ensino de Língua Portuguesa, como revela, deve estar baseado na resposta à questão do "para quê ensinamos", e esta envolve uma concepção de linguagem.

Esse autor enumera três concepções de linguagem: a linguagem como expressão do pensamento, como instrumento de comunicação e como forma de interação. A primeira corresponde à corrente dos estudos da gramática tradicional, a qual nos leva a entender que as pessoas que não conseguem se expressar, não pensam. A segunda retoma a teoria da comunicação e concebe a língua como um código que deve ser usado pelo emissor para transmitir ao receptor uma mensagem. A terceira corresponde à linguística da enunciação, para a qual a linguagem deve ser percebida como espaço de interação humana. Como explica o autor, as concepções de linguagem implicam uma postura educacional diferenciada, uma vez que posicionam a linguagem no âmbito das práticas sociais em que falantes se configuram como sujeitos.

Considerando a concepção interativa da linguagem, é possível pensar o ensino da produção escrita de forma processual, com professor e aluno interagindo pela linguagem. No sentido de favorecer essa relação em que o professor faz a correção e o aluno a revisão do texto, Serafini (1998, p. 119) recomenda que é "fundamental fornecer aos alunos uma planilha de análise". Aponta que eles "têm que perceber com clareza que a correção deve contribuir para o aperfeiçoamento do texto em alguns de seus aspectos específicos, sobre os quais o autor possa trabalhar" (p. 119). Sendo assim, é necessário que o professor estabeleça critérios para que o aluno possa revisar seu texto, critérios que futuramente constituirão os critérios de avaliação do professor, sua devolutiva ao aluno.

Mas não se pode dizer que essa consideração ocorre nas chamadas aulas de redação, pois, na maior parte de tempo, as aulas da Língua Portuguesa são destinadas a questões de metalinguagem com exercícios de análise da língua (GERALDI, 2007). Assim, pouca utilidade encontrará o aluno, pois, conforme Geraldi (2007), os estudos linguísticos têm a função de auxiliar o estudante a compreender alguns fenômenos e ocorrências na língua, como forma de contribuir para o processo de elaboração de sua produção escrita. Saber nomenclaturas e memorizar determinadas ocorrências, como mero exercício metalinguístico, em nada favorecerá o estudante na construção de sua competência linguística. Passarelli (2008b, p.81) retoma essa questão mencionando que é "pela reflexão sobre a língua em função que se chega ao sistema que a regula". 
De acordo com Serafini (1998, p. 155), várias pesquisas mostram que, para o aprendizado da produção de texto, “[...] pouco vale o estudo sistemático da gramática [...]” se estiver separado da atividade concreta da escrita; ao contrário, serão muito úteis tais conceitos se forem necessários a um texto específico.

Com isso, o que se quer apontar é que o processo de ensino parece estar invertido: as práticas partem de análises linguísticas, quando se deveria partir desses textos para as análises, fazendo um levantamento dos itens que se mostram mais necessários ao trabalho linguístico.

Além desses aspectos discutidos, observamos, ainda, que o ensino da produção escrita, em grande parte, está restrito aos modos de organização textual, ou seja, à tipologia textual composta pela tríade descrição, narração e dissertação, sem, contudo, considerar o ensino por meio dos gêneros textuais/discursivos e seu funcionamento social. De acordo com Lopes-Rossi (2002, p. 19), esse tradicional ensino vem sendo posto em discussão desde o início dos anos 80 por diversas pesquisas na área da Linguística e da Linguística Aplicada. Essa autora aponta que as primeiras apresentavam enfoque nos aspectos linguísticos como coesão e coerência textuais e nos problemas gramaticais. Em seguida, outras temáticas como "as interações na produção escrita” e "a prática docente” se colocavam no centro das atenções. As conclusões, em sua maioria, revelavam “[...] um ensino comprometido por sérios problemas conceituais, conteudísticos, pedagógicos, como se pode constatar por vários autores tais como: Pécora (1983), Brito, (1985), Geraldi (1993), Fiad e Mayrink-Sabinson (1991).” (apud LOPES-ROSSI, 2002, p. 20).

Apesar das relevantes conquistas teóricas no campo da Linguística Aplicada, Lopes-Rossi (2002), após pesquisa em livros didáticos, alerta, ainda, para o fato de muitos livros didáticos ainda manterem tal tradição e de muitos professores recorrerem a eles para o trabalho em sala de aula de forma exclusiva. Há que se observar, no entanto, que algumas das publicações mais recentes de livros didáticos demonstram certa tentativa de reformulação da proposta de ensino de produção escrita voltada para os gêneros, embora sejam propostas ainda incipientes. A autora revela que, aparentemente, tais reformulações podem parecer interessantes e atualizadas, mas, numa análise mais detalhada, nota-se certa insuficiência na exploração do gênero em sala de aula e uma “[ [...] proposta de produção que parece não contribuir significativamente para o desenvolvimento da capacidade comunicativa do aluno, além de não incorporar valores de uma concepção sócio-histórica da linguagem [ [...]” (2002, p. 24).

Lopes-Rossi conclui que há uma grande diversidade de gêneros textuais nesses livros, porém, cada um deles é abordado de forma rápida e superficial. Observou que são raras as propostas que estimulam o contato do aluno com o texto original, exemplos reais de gêneros pretendidos para o estudo, pois a reprodução do gênero nos livros didáticos não corresponde fielmente ao original no que diz respeito, por exemplo, aos aspectos gráficos, comprometendo, assim, o entendimento das características composicionais do gênero, além de outras.

Quanto às propostas propriamente ditas, segundo a autora, apresentam-se de forma isolada, sem continuidade ou vínculo a um projeto pedagógico; os questionamentos enfocam aspectos que se restringem ao conteúdo textual, desconsiderando a relevância do enfoque nas condições de produção e de circulação dos gêneros. Além disso, os aspectos não verbais são ignorados nas propostas, e a culminância delas conduz os alunos a inventar dados e imaginar informações irreais que não contribuem para a percepção das reais condições de produção de cada gênero de texto. Corre-se o risco, como afirma Lopes-Rossi, de os alunos chegarem a pensar que, por exemplo, a capa de uma revista ou uma reportagem são textos de invenção dos jornalistas e não frutos de uma prática social efetiva e real, de busca de informações e de pesquisas. Observa, também, que, nas propostas de escrita, não há espaço para o acompanhamento da produção e que a maior parte delas se configura como mero exercício escolar, visto que o destino dos textos é o caderno ou a mesa do professor, não havendo, portanto, um propósito de circulação social daquele texto como aconteceria de fato com um texto que circula em nossa sociedade.

Para sintetizar tais reflexões, recorra-se a Antunes (2006, p. 50), que aponta a escrita do meio escolar como “[...] uma escrita sem função, artificial, mecânica, inexpressiva, descontextualizada, convertida em puro treino e exercício escolar, que não estimula nem fascina ninguém, pois se esgota nos reduzidos limites das próprias paredes escolares." Consequentemente, “[ $\ldots .$.$] a realidade de nossas salas de aulas mostra a falta de$ esforço, a improvisação e a pressa com que nossos alunos escrevem.” (ANTUNES, 2006, p. 57).

Soares (apud COSTA, 2008) aponta que estamos vivendo uma mudança de paradigma no ensino do português. Esclarece que são duas as causas dessa mudança. A primeira refere-se ao desenvolvimento das 
ciências linguísticas; a segunda é a democratização do ensino. A autora esclarece que o eixo de ligação entre as duas causas está na Sociolinguística e na teoria dos gêneros, pois a Sociolinguística surge como forma de estudo e controle das manifestações de preconceitos linguísticos contra alunos provenientes de contexto social cultural e linguístico diferente daqueles da classe média e alta, os quais, com a democratização do ensino, têm acesso à escola. Por outro lado, a teoria dos gêneros veio somar-se aos tipos textuais de largo domínio no ensino da leitura e escrita, ou seja, a narração, a descrição e a dissertação, que ignoram “[…] aquilo que verdadeiramente institui e constitui o texto: os aspectos sócio-históricos e interativos que definem seu funcionamento e resultam de seu contexto de produção e recepção [...]”. (SOARES apud COSTA, 2008, p.7).

Como revela a autora, essa nova teoria, aos poucos, foi sendo acolhida no ensino da língua materna, pois aos textos escolares, de comum utilização, somam-se outros gêneros pertencentes a outras esferas da sociedade. Expõe, ainda, que toda mudança gera novas dificuldades, o que exige novos comportamentos, novas acomodações de ideias. Em relação à Sociolinguística, explica que tem sido um problema de difícil solução o reconhecimento das variedades linguísticas devido a resistências de ordem política e ideológica, “[...] calcadas em séculos de uma concepção elitista da língua e de seu uso.” (SOARES apud COSTA, 2008, p. 08).

Quanto aos novos conceitos relativos à teoria dos gêneros, Soares explicita que os problemas são de outra natureza. Referem-se às dúvidas teóricas e pragmáticas que advêm da precária disseminação, entre os professores, dessa recente teoria que surge no Brasil nas produções acadêmicas nas na metade dos anos 90. Explica que existe uma lacuna na formação dos professores sobre a compreensão dos conceitos e sobre a orientação para o trabalho adequado com os gêneros textuais no ensino da língua portuguesa.

Nesse sentido, Antunes (2009, p.52) explica que, com a divulgação dos Parâmetros Curriculares Nacionais (PCN), entrou em cena uma mudança de perspectiva e "uma ampliação de paradigma, que afetariam [...] a concepção de língua, de gramática, de texto, de frase e, assim, a redefinição do objeto mesmo de ensino".

De acordo com o exposto, percebe-se que o quadro do ensino do português encontra-se num período de transição. Como apontou Soares (apud COSTA, 2008), existem, por parte do professor, muitas dúvidas relativas à nova teoria, mas, apesar delas, algumas tentativas de ajustar o trabalho às novas recomendações teóricas estão sendo feitas, mesmo que incipientes e com lacunas.

Professores arriscam elencar certo número de gêneros textuais para ensinar seus alunos a produzi-los, porém, muitos deles se deparam com o insucesso de tal prática. Alguns dos motivos que os levam a esse insucesso são de ordem conceitual e metodológica, pois, como afirma Passarelli (2008b), qualquer prática pedagógica que se desenvolva sob essa perspectiva necessita de mudanças de ordem metodológica, a qual decorre da necessidade de o professor dominar conceitos e estratégias para melhor conduzir seus alunos a compreenderem os gêneros bem como saber produzi-los nas situações em que são exigidos na vida em sociedade.

Convivemos, assim, com muitos docentes que mantêm práticas tradicionais e alguns poucos que procuram tais ajustamentos. Mendonça (2009) comenta que esse novo tipo de abordagem requer mais estudo, tarefa que já está sendo feita por vários pesquisadores. Afirma que, até que se elabore uma organização curricular mínima que sirva de ponto de partida para a elaboração de currículos e programas nas mais diversas instâncias de decisão educacional, será comum a existência de perspectivas diferentes de trabalho durante um bom tempo.

\section{O ENSINO POR MEIO DOS GÊNEROS: A FUNÇÃO}

Em meio a inúmeras discussões acerca do ponto de partida para o ensino de Língua Portuguesa, Meurer e Motta-Roth (2002) abordam as exigências do mundo contemporâneo. Afinal, o sujeito aprendente que se dirige ao espaço escolar o faz não para a realização de tarefas inócuas, que em nada lhe favorece sua vida social, mas como forma de ampliar sua competência de agência no espaço em que vive. Ele próprio como sujeito no construto de sua história.

Para sua ação no mundo, o sujeito encontra na linguagem a fonte mediadora do seu discurso, pois é por meio dela que comunicamos fatos, fazemos declarações, nos posicionamos sobre determinadas discussões, tentamos persuadir os outros às ações de nosso interesse. Enfim, uma gama de possibilidades efetivas de 
linguagem que exige a emergência de “[...] novas práticas educacionais relativas ao uso de diferentes gêneros textuais e aos requisitos de um letramento adequado ao contexto atual.” (MEURER; MOTTAROTH, 2002, p.10).

Para confirmar essa função da linguagem, Marcuschi (2008) explicita que é impossível não se comunicar verbalmente por meio de gêneros, pois toda manifestação de linguagem ocorre sempre por meio de textos realizados em algum gênero textual. Esse autor define gêneros textuais como textos materializados a partir de situações comunicativas recorrentes. São textos que se encontram no dia a dia e apresentam padrões sociocomunicativos. O autor explica, ainda, que, ao dominarmos um gênero textual, não dominamos uma forma linguística, mas uma forma de realizar linguisticamente objetivos específicos em situações sociais particulares.

De acordo com Cristóvão (2002), diversos autores, como Dolz e Schneuwly, propõem a abordagem em sala de aula dos gêneros textuais. Eles definem a noção de gêneros de textos como uma maneira de formar os gêneros impostos no decorrer da história que constituem, para o usuário da língua, como modelo e instrumento necessário para suas atividades de leitura e escrita. Essa definição aponta para o trabalho com o ensino de gêneros textuais no processo de ensino aprendizagem. Entre outros trabalhos, Cristóvão (2002) ainda ressalta que Machado e Brandão desenvolvem projetos na área de ensino-aprendizagem, apontando o gênero e sua descrição como foco de pesquisa. À luz do interacionismo sócio-discursivo, esses autores seguem o modelo de análise de texto, para caracterização dos gêneros, proposto por Bronckart. Em Brandão (apud CRISTÓVÃO, 2002), nota-se o foco do trabalho com os gêneros como possibilidade de desenvolver um leitor crítico.

Bazerman (2006, p. 9) afirma que a abordagem do gênero é uma atividade que pode "apoiar o crescimento dos estudantes como escritores e agentes efetivos, realizando coisas no mundo através de sua escrita”. Lembra que os estudantes são simplesmente pessoas que se dirigem à escola para ampliar suas possibilidades de ter sucesso em sua vida e contribuir com o meio social, uma vez que é na sala de aula que se encontra a chance de promover o desenvolvimento da maioria dos membros da sociedade.

Prossegue o autor, destacando que o ensino de gêneros não pode ser visto apenas como uma pedagogia formal, pois seriam evocadas todas as dificuldades de motivação, compreensão, da mesma maneira quando se tenta ensinar a alguém algo destoante dos seus interesses e experiências pessoais. O ensino desvinculado de seus usos emerge sem sentido e se conforma à pura " $[\ldots]$ subjugação a sistemas de ordem impostos, em vez de ser a provisão de ferramentas úteis para a vida que os estudantes podem adquirir para seus propósitos pessoais" (BAZERMAN, 2006, p.10).

Conforme Bazerman (2006), a abordagem do gênero deve ser vista como uma ação pela qual podemos tornar as intenções compreensíveis aos outros e não mero conteúdo formal, pois o gênero é uma constituição material resultante das ações e intenções humanas, não podendo, portanto, ser ensinado de forma desvinculada da ação e das situações dentro das quais aquelas ações são significativas. Isto significa que o ensino do gênero 'notícia', por exemplo, deve ser feito associado às suas condições de produção, de circulação, favorecendo ao aprendiz a percepção de como esse texto se constitui no âmbito da prática social do jornalismo.

Esse autor partilha da ideia de que, por resultar das práticas sociais humanas, os gêneros devem ser ensinados atrelados ao contexto em que se realizam. Apresenta-nos, então, a noção de agência. Explica que uma realização escrita é uma forma de agência sobre o mundo. Para exemplificar, cita autores como Machado de Assis, Shakespeare, Platão, Darwin, os quais, ao usarem a ferramenta da linguagem escrita, tornaram-se agentes, pessoas que têm ampliado e reformulado o pensamento e a ação da comunidade. Ressalta, no entanto, que não são apenas as grandes figuras históricas que expressam agência por meio da escrita, mas cada pessoa que se utiliza da ferramenta. Exemplifica, também que cada vez que um estudante escreve um artigo, mesmo que com única pretensão a uma nota alta, da mesma forma está sendo agente de seus interesses individuais. Por isso, cada vez que um jornalista, um vendedor, um professor, um advogado escrevem para realizar simplesmente uma tarefa profissional, na verdade estão “[ [...] atuando como agente, ao ganhar a vida e ao fazer avançar positivamente o trabalho de sua profissão ou organização da qual faz parte." (BAZERMAN, 2006, p.12).

Bazerman (2006) reflete que desde cedo os alunos aprendem que a função da escrita escolar é demonstrar suas habilidades linguísticas, o que significa expor suas fraquezas, seus erros. A produção textual escrita 
como tarefa meramente escolar conduz os alunos a pensarem que sua função é para ganhar a aprovação de uma autoridade, que os deixa com receio de eles serem corrigidos, crença que lhes acaba negando todas as outras possibilidades de realização com a escritura. Resultante dessa escrita abstrata, dada numa esfera de exposição pessoal e mera avaliação, a produção do aluno acaba por "[ [...] se tornar vazia, dizendo nada a ninguém, por nenhuma razão." (p. 15). Uma visão social da escrita, contudo, pode auxiliar a desenvolver uma pedagogia que ensine os alunos a perceber os gêneros não somente como formas textuais mas também como formas de vida e de ação. Quando os alunos perceberem que seus textos podem " [ ...] ter vida para leitores à distância, criando interação dos significados evocados pelo texto, eles terão alcançado a agência mais profunda da escrita." (BAZERMAN, 2006, p. 21).

Sobre a função dos gêneros no ensino de Língua Portuguesa, Gaydeczka (2006, p. 85) revela que os PCN evidenciam que a língua se realiza nas práticas sociais a partir das ações dos sujeitos e que, com isso, consideram que a finalidade do ensino de língua materna “[ [...] é garantir a expansão das possibilidades de uso e reflexão da linguagem em situações significativas de interlocução, adquirir capacidade [...] relacionada às habilidades: falar, ouvir, escutar, ler e escrever [ $\ldots .$.$] ”, tomando o texto como unidade de$ ensino, percebendo-o em sua diversidade e circulação social.

Em consonância, Antunes (2006, p. 44) conclui que os “[...] fatos da língua somente vêm à tona nas práticas discursivas, das quais o texto é parte constitutiva. Por isso, é que só os textos podem constituir o objeto relevante de estudo da língua." [grifos da autora].

Para Passarelli (2008b, p. 75-76), o objetivo maior do ensino da língua é o de "[...] ampliar e desenvolver a competência linguística dos aprendentes, para que eles possam compreender e criticar textos e tenham a capacidade de avaliação e criatividade no manejo da língua". Tal objetivo se delineia no âmbito de uma educação linguística. Segundo a autora, nessa perspectiva, "[...] o professor orienta o aluno para que ele adquira o saber linguístico e o leve a escolher adequadamente as modalidades a usar de acordo com o contexto" (p. 76). Para tanto, orienta que o gênero seja tomado como objeto de ensino, considerando seu funcionamento social e contextual, sua forma e conteúdo. No entanto, ressalva que práticas pedagógicas que se desenvolvam sob essa perspectiva demandam mudanças metodológicas e necessidade de o professor ter domínio de conceitos e estratégias para melhor conduzir seus alunos a compreenderem os gêneros bem como saber produzi-los nas situações da vida em sociedade em que são exigidos.

Para corroborar, Mendonça (2009, p. 199-202) aponta um possível problema na organização da grade curricular do Ensino Fundamental e Médio que se assemelha ao sumário da gramática normativa: da fonologia para a morfologia, daí para sintaxe, para a semântica da frase onde parecem finalizar os fenômenos linguísticos. A lógica que subjaz a essa organização, como expõe a autora, é a sucessão de unidades a serem analisadas com gradação de complexidade. Estuda-se a palavra, a oração, o período, porém, raramente se chega à unidade maior - o texto - e, menos ainda, aos gêneros textuais.

O que se tem em vista é a necessidade de organizar o currículo de modo a integrar o eixo de leitura, produção textual e análise linguística, pois o modelo tradicional do ensino da gramática normativa acaba por contribuir para a formação de analistas da língua. Mendonça (2009, p. 204) expõe que não é objetivo da escola formar gramáticos ou linguistas descritivistas, mas “[ [...] pessoas capazes de agir verbalmente de modo autônomo, seguro e eficaz, tendo em vista os propósitos das múltiplas situações de interação em que estejam engajadas".

Nesse contexto, a autora comenta que Dolz e Schneuwly ([1996] 2004 apud MENDONÇA, 2009) sugerem um trabalho sob a perspectiva dos gêneros, ou seja, que

\footnotetext{
[...] a progressão escolar se organize em torno da exploração de habilidades necessárias à leitura e produção de gêneros pertencentes aos diversos agrupamentos: do relatar (narrativas não ficcionais), do narrar (narrativas ficcionais), do descrever ações (textos instrucionais e prescritivos) do expor e do argumentar. Em todos os momentos de escolarização, os alunos seriam levados a refletir sobre a organização de gêneros diversos, pertencentes aos vários agrupamentos. (p. 218).
}

Assim, tendo em vista a estreita relação entre os gêneros e a atividade humana, o estudo dessas formas textuais, em sala de aula, configura-se fundamental ao aprendizado das formas de atuação sócio-históricas. 


\section{OS GÊNEROS NA SALA DE AULA: UMA ABORDAGEM PRODUTIVA}

Procurando contribuir para a melhoria do ensino e diante dos estudos acerca da teoria de gêneros, inúmeros têm sido os subsídios teóricos e elucidativos para situações práticas em sala de aula. Lopes-Rossi (2002) propõe que o ensino dos gêneros discursivos seja desenvolvido por meio de projetos pedagógicos estruturados em módulos didáticos, os quais já têm sido desenvolvidos com sucesso em escolas públicas e particulares no interior de São Paulo. Sua proposta contempla três módulos. O primeiro deve levar o aluno a conhecer as condições de produção e de circulação do gênero escolhido para trabalho, tomando ciência do real suporte pelo qual é veiculado - podendo ser jornal, revista, rótulo, folder etc. Aponta que “[...] esse nível de conhecimento permite uma série de inferências, por parte do leitor, para a escolha vocabular, o uso de recursos linguísticos e não-linguísticos” (p. 84), proporcionando-lhes, gradualmente, a percepção da relação entre os sujeitos e a linguagem e a percepção do caráter sócio-histórico do gênero. Além disso, como defende a autora, a sequência de atividades desse primeiro módulo favorece o desenvolvimento de habilidades de leitura, preparando-os para a produção escrita, pois nesse módulo é contemplado o estudo da organização composicional do gênero, conhecimento básico de que necessita o aluno para a sua produção. Dessa forma, no âmbito de um projeto, Lopes-Rossi (2002, p. 86) comenta que “[...] fica mais clara e eficiente a contribuição que a leitura pode dar ao processo de produção escrita." Contudo, faz a seguinte ressalva: “[...] não é o caso de se oferecerem apenas modelos para os alunos reproduzirem. É o caso de darlhes a oportunidade de desenvolver a competência comunicativa pela apropriação das características típicas do gênero em estudo." (p. 86).

O segundo módulo didático compreende o ensino da produção escrita e pressupõe obtenção de informações, pois, para sua realização, é necessário que seja de acordo com as condições de produção em nossa sociedade. A autora exemplifica, citando a produção de uma reportagem, para a qual o jornalista faz uma entrevista, tira fotos, observa a realidade, colhendo informações, pesquisa em fontes impressas, elabora sua primeira escritura e revisa seu texto. Assim os alunos devem proceder se desejarem escrever uma reportagem. A autora orienta para que essa sequência de atividades se realize em várias horas-aula, para a obtenção de informações necessárias ao texto. Encerra a apresentação desse módulo, explorando a ideia de que os próprios alunos devem revisar e corrigir seus textos com a colaboração dos colegas, obtendo, posteriormente, a intervenção do professor para a sua refacção, se necessário. Considera essa etapa de revisão a oportunidade de identificar as dificuldades gramaticais dos alunos para usá-las em exercício de análise linguística em outras aulas.

Por fim, o último módulo didático corresponde à divulgação ao público. Conforme Lopes-Rossi (2002), é um momento que requer algumas providências como organização de um mural ou uma exposição para que sejam divulgados os trabalhos dos alunos de acordo com a forma típica de circulação do gênero. Esse módulo constitui uma parte importante do desenvolvimento do processo de escritura, pois, desde o início do processo, poderá ser explicitado ao aluno que o professor não será o único leitor do seu texto. "Cabe ao professor, portanto, criar condições para que os alunos possam apropriar-se de características discursivas e linguísticas de gêneros diversos em situação de comunicação real”, ressalta Lopes-Rossi (2002, p. 30).

De um modo geral, a proposição desse trabalho, a partir de sequências didáticas desenvolvidas ou não a partir de projetos pedagógicos, apresenta-se como uma forma de favorecer o entendimento do que afirma Passarelli (2004, p. 35):

Antes de ser um objeto escolar, escrita é um objeto social. Assim, a tarefa da escola é levar o aluno a perceber o significado funcional do uso da escrita (e da leitura), propiciando-lhe o contato com as várias maneiras como ela é veiculada na sociedade. Daí a relevância de aproximar os usos escolares da língua escrita com o aspecto comunicativo dentro e fora do contexto escolar.

Observamos, também, em Passarelli (2004), que a escritura constitui um processo que exige planejamento, revisão e reescrita. Por isso, aliado à perspectiva de conhecer o gênero em suas características específicas, o momento da escritura deve contemplar as fases de produção e não mais as tradicionais produções imediatas.

\section{A PRODUÇÃO ESCRITA: CORREÇÃO E DEVOLUTIVA DO PROFESSOR AO ALUNO}

Durante muito tempo, a palavra 'correção', e suas variações, tinha uma conotação negativa ao lado do vocábulo "erro", passando, inclusive, a ser evitada nos contextos relacionados ao ensino-aprendizagem. Dessa forma, outros vocábulos e expressões passaram e ser usados como 'devolutiva', 'intervenção' e 
'inadequação'. A justificativa que comumente perpassa essa mudança terminológica e epistemológicas está centrada no papel do professor. Antes, como detentor exclusivo de todo o saber, cabia ao professor examinar a produção e apontar os erros ao aluno - "tabula rasa" - que nada sabia. Hoje, subjacente às mudanças terminológicas, está o novo papel do professor: não mais aquele da posição verticalizada e distanciada do ensino, que apenas determinava o que era correto, mas aquele que, na posição horizontal, ao lado do aluno, auxilia-o na (re) elaboração do tex to escrito.

Ao mencionarmos a expressão 'devolutivas do professor ao aluno', estamos tratando especificamente da forma como o professor tem corrigido ou não as redações dos alunos. Entendemos por correção "[...] o texto que o professor faz por escrito no (e de modo sobreposto ao) texto do aluno, para falar do mesmo texto." (RUIZ, 2010, p. 19). Essa correção constitui-se em uma atividade de interação com o aluno. Desempenhando o papel de leitor desse texto do aluno e como coautor, ao produzir suas correções, o professor está realizando devolutivas, devolvendo-lhe o que pensa e sabe, dialogando com o aluno acerca da feitura de seu texto. Da mesma forma, ao fazer uso da expressão processo interventivo, estamos tratando igualmente de uma forma interativa de corrigir, de o professor ser coautor da produção escrita do aluno.

Por isso, neste estudo, desconsideramos a conotação atribuída, muitas vezes negativa, ao vocábulo correção, considerando-o tão somente como sinônimo de devolutiva e de intervenção. Quanto ao vocábulo "erro", igualmente será visto, isto é, sem dar relevância ao conteúdo semântico negativo que lhe foi atribuído ao longo dos anos. Consideramos erro aquilo que não atende à situação comunicativa específica, determinada para o contexto de produção escrita ou aquilo que, em uma comparação entre os níveis formais e informais da linguagem, não está de acordo com o padrão culto da linguagem.

Da mesma maneira, é necessário aqui pontuar sobre a palavra 'redação'. Durante décadas, grandes mudanças ocorreram, em termos teóricos, quanto ao ensino do texto escrito e às denominações usadas para esse processo. Inicialmente, o texto escrito denominava-se "composição", passando, depois, para "redação" (BUNZEN, 2006, p. 139-161). Ambos, porém, traziam consigo a conotação do que hoje se entende por temas descontextualizados. Ou seja, um tema de composição ou redação costuma ser visto como propostas dissociadas da vida do aluno, artificiais, sem propósito de existência. Nesse contexto, e diante dos estudos dos gêneros e da divulgação dos PCN, a terminologia empregada para denotar uma prática interativa de linguagem passou a ser produção escrita ou produção de texto. Nessa perspectiva, o professor revelaria uma mudança de postura quanto ao ensino do texto escrito: em caráter interacional, apresenta-se como corresponsável na construção do texto escrito, isto é, o professor seria aquele que auxilia o aluno em todas as etapas de elaboração do texto.

Embora ainda existam práticas artificiais de ensino do texto escrito, é preciso apontar que nem sempre a terminologia empregada determina o posicionamento adotado pelo professor. Segundo Geraldi (2007), acredita-se que o que interfere no trabalho a ser desenvolvido em sala de aula é a concepção de linguagem adotada pelo professor, conforme definições já explicitadas anteriormente. Neste trabalho, que se ancora na concepção que toma a linguagem como forma de interação, as terminologias produção escrita, produção de texto e redação serão vistas de forma intercambiáveis.

Já se apontou anteriormente que o enfoque dado à produção escrita no ambiente escolar não contempla o ensino da escrita de forma processual. Ou seja, comumente oferece-se um tema ao aluno, solicitando sua escritura, sem, contudo, possibilitar-lhe a chance de uma revisão. O aluno escreve, o professor corrige, devolve a produção com a nota. Por sua vez, o aluno guarda sua produção ou dela se desfaz. Essas práticas, consideradas tradicionais, limitam-se a "[ $[\ldots]$ simplesmente tingir de vermelho o texto e devolvê-lo para o aluno, parando o processo nessa etapa” ('RUIZ, 2010, p. 12). Dessa forma, fica claro que o aluno quase não possui oportunidade de evoluir em sua escrita.

Em contrapartida, uma proposta que signifique, para o aluno, evolução de seu texto escrito, passa pelo viés processual. Ou seja, considera-se que, após a produção escrita, o professor realize suas intervenções, devolva o texto ao aluno, solicite-lhe que reveja as sugestões dadas e que o reescreva, eliminando e/ou alterando as falhas e incluindo informações necessárias.

Considerando essa perspectiva processual, diversas são as estratégias de correção que podem ser utilizadas. RUIZ (2010, p. 35) revela que o professor pode, durante a correção, produzir traços, sinais abreviaturas, expressões, comentários, "[…] ora na margem, ora no corpo, ora no pós-texto". 
De acordo com Serafini (1989, apud RUIZ 2010, p. 35), existem três grandes tendências de correção de redações: a indicativa, a resolutiva e a classificatória. Serafini (1998) define a correção indicativa como aquela que consiste em marcar junto à margem as palavras, frases e períodos inteiros que apresentam erros ou que estão pouco claros. Nesse tipo de correção, o professor apenas sinaliza que há um erro em determinado local, mas não oferece uma solução para o erro. Por exemplo, na frase Ainda que eu tinha ido à praia..., ele indica o erro com um traço sob o verbo "tinha".

A correção resolutiva, por sua vez, é definida como aquela que consiste em corrigir todos os erros e oferecer ao aluno uma solução. Nesse tipo, o professor reescreve palavras, frases, períodos inteiros, fornecendo possibilidades corretas. Desse modo, não sinalizaria apenas o erro, mas apresentaria uma resolução para a inadequação cometida, como na frase Ainda que eu tinha ido à praia..., acrescentando o verbo correto "tivesse" ao lado ou abaixo do verbo "tinha".

Já a correção classificatória consiste em classificar o tipo de problema apresentado pelo aluno. Nesse tipo de correção, é preciso que haja um acordo estabelecido entre professor e aluno, pois classificar a origem de um problema significa que esse problema é de conhecimento do aluno. No exemplo dado, o professor classificaria o problema, indicando com a palavra "modo", pois o erro apresentado na frase apresentada diz respeito a uma inadequação quanto ao modo verbal do verbo "tinha".

Da mesma forma, se a origem do problema fosse "concordância verbal", o professor classificaria para o aluno como "CV", conforme se verifica no exemplo: Os meninos estava no parque. $C V$.

Após apresentar essa três formas de correção, Serafini (1998) comenta que, nas correções indicativa $e$ resolutiva, prevalece uma atitude descritiva e na correção classificatória, uma atitude operativa. Nas primeiras, isso significa que o erro é apontado, descrito e resolvido para o aluno. Assim, menor será a sua participação no processo de correção. Sua tarefa restringir-se-á a apagar o inadequado e consertá-lo, ou buscar outra forma de dizer aquilo que errou, sem saber a origem, a natureza de seu erro. A autora ainda discute que as correções classificatórias são aquelas que mais auxiliam o aluno a melhorar a sua redação, pois conhecerá a origem do erro que cometeu ao corrigi-lo, fato que, provavelmente, o impedirá de cometer o mesmo erro futuramente. Diferentemente das primeiras correções, esta não oferece uma resposta pronta, mas conduz o aluno a pensar sobre seu erro.

Ruiz (2010), ao desenvolver uma pesquisa partindo desses tipos de correções apresentadas por Serafini, concluiu que as menos utilizadas pelos professores são as do tipo classificatórias. Concluiu, ainda, que, nas correções resolutivas somente o professor reflete sobre o texto, e que, nas classificatórias e nas indicativas, ambos, professor e aluno, são conduzidos a refletir. A autora explica que há uma diferença fundamental entre essas intervenções. A primeira, Ruiz (2010) classifica como monológica, por considerar que a resposta do professor anula totalmente a presença do aluno no texto, privando-o de sua participação. Ao contrário, as intervenções classificatória e indicativa apresentam um caráter dialógico por solicitar do aluno uma atitude responsiva. Nessas intervenções, o aluno é conclamado a agir, a pensar e a oferecer uma resposta, não permanecendo passivo nesse processo de revisão de seus erros.

Ruiz (2010) amplia essa noção de estratégia de correção, apontando que o professor também faz uso de "bilhetes". Isto é, na redação de seus alunos, constrói bilhetes de natureza diversa, tais como: elogiar uma tarefa bem feita, cobrar algo que o aluno poderia ter feito melhor e, sobretudo, quando as estratégias de correções anteriormente explicadas não se colocam como suficientes. É o caso de quando a falha cometida pelo aluno extrapola o âmbito da palavra ou frase, atingindo o âmbito textual. Para Ruiz (2010), se o problema estiver no âmbito microestrutural e superficial do texto, maior a probabilidade de se utilizar as estratégias resolutiva, indicativa e classificatória. Em contrapartida, se estiver no âmbito macroestrutural e profundo do texto, maior a utilização de bilhetes. A autora justifica essa diferença, apontando que as primeiras estratégias permanecem vagas e imprecisas para o aluno, se o problema for de ordem profunda. Por isso, os professores costumam recorrer aos "bilhetes" para tornar claro o problema.

Para exemplificar o que se considera como um problema que extrapola o âmbito da palavra e da frase, reproduz-se, a seguir, o conteúdo de um bilhete deixado por uma professora, ao final da redação de uma aluna, redação essa que constitui parte do corpus de pesquisa de Ruiz (2010, p.152): Você desenvolve uma série de ideias pertinentes ao tema, mas parece que o ponto-de-vista ficou difuso. Tente ser mais clara quanto à sua opinião e aos seus argumentos. Eliana, 26/set. 
Nesse exemplo, a professora procedeu a uma orientação de ordem global, isto é, percebeu que, embora sua aluna esboçasse uma tomada de posição, não a tornava decorrente do encaminhamento que deu ao tema, não esclarecendo inclusive a relação entre posicionamento adotado e argumentos. Isso significa que o problema situava-se no âmbito global do texto, perpassando as relações não estabelecidas entre os parágrafos. Nesse caso, as outras estratégias seriam insuficientes para esse tipo de problema de redação.

Apesar dessas orientações, pode-se notar que ainda há grandes dificuldades por parte dos professores em realizar uma proposta de redação que contemple a revisão e a devolutiva ao aluno. Dentre as possíveis causas desse problema, podemos citar: o desconhecimento do professor sobre a perspectiva processual de ensino de redação, a sua má formação e a própria viabilidade do trabalho docente, tendo em vista o grande número de alunos que frequenta a escola pública.

Considerando-se esse cenário, destaca-se, no entanto, o pouco espaço que o processo de produção e correção de texto tem tido no Ensino Fundamental I. Em relação à bibliografia pesquisada, não se encontrou uma obra que, pontualmente, apresentasse uma possibilidade efetiva de correção de texto dirigida aos professores desse nível de ensino².

De modo geral, a escassez de trabalhos que tratam especificamente de estratégias de como fazer o aluno evoluir em suas produções de texto explica, em parte, o insucesso dos estudantes quanto à competência escritora. As obras citadas neste estudo para tratar de estratégias de correção fazem parte de um universo pouco explorado e focalizam o público do Ensino Fundamental II, isto é, um público com noções de texto mais amadurecido em relação aos alunos do $4^{\circ}$ e $5^{\circ}$ anos do Ensino Fundamental I.

\section{PROCEDIMENTOS PARA CORREÇÃO DE TEXTOS DE ALUNOS DO EF I}

Considerando a escassez de material que trate especificamente de estratégias que visem à evolução do texto escrito de alunos do $4^{\circ}$ e $5^{\circ}$ anos do EF I e à experiência que temos tido com o referido público, ocupar-nosemos, nesta seção, de oferecer algumas possibilidades de ensino que têm trazido bons resultados. A escolha dessas séries deve-se ao fato de que, nesse período, a maioria dos alunos, provavelmente, encontra-se alfabetizada e em condições de produzir texto. Deve-se, também, ao fato de que muitos docentes trazem consigo dúvidas sobre como trabalhar a produção de textos nesses anos finais do EF I. É importante frisar que, também nesse nível, o ensino da produção textual deve possuir um caráter processual e partir do ensino de gêneros, como recomendam muitos autores já citados.

Primeiramente, desde cedo é necessário o aluno aprender que os textos precisam ser revisados e que ele próprio deve ser o primeiro leitor de seu texto. É nessa fase que o professor pode iniciar o desenvolvimento desse hábito de leitura, para que o aluno se habitue a ler, logo após terminar de escrever. E ainda: desenvolver a noção de que o professor fará a leitura desse texto como segundo leitor e como um leitor um pouco mais experiente, fazendo observações, correções, a fim de que o aluno possa aperfeiçoar sua escrita, pois já se apontou que até os escritores revisam suas produções.

Além disso, outra orientação ao professor é que tenha como ponto de partida um gênero com identidade própria, pois a comunicação humana ocorre por meio de gêneros, sejam escritos ou orais. Podem-se tomar como ponto de partida bilhetes, cartas pessoais ou carta do leitor, pequenos contos (que normalmente já fazem parte do universo desse público como ouvinte e leitor), pois são gêneros mais simples ${ }^{3}$ de se apropriar devido às características composicionais para a produção escrita, até se chegar a outros gêneros como a notícia, que exigirá maior habilidade e destreza com a linguagem. Dessa forma, contemplando um gênero, é possível ampliar o escopo de observação do professor no ato da correção, não se restringindo apenas à ortografia e aos aspectos normativos da gramática. Outros aspectos ganhariam espaço, tais como: as características composicionais do gênero, a variação de registro (formal e informal), a organização textual, as condições de produção (o autor, o público a quem o texto se dirige, o objetivo do autor etc.).

\footnotetext{
2 As nomenclaturas são diversas conforme a região. Em algumas localidades, emprega-se Fundamental I para se referir ao público de $1^{\text {a a }} 4^{\mathrm{a}}$ série, isto é, o público do $1^{\circ}$ ao $5^{\circ}$ ano; em outras, usa-se a expressão Ciclo I, denominações essas que se empregam em oposição ao Fundamental II ou Ciclo II para referirem-se ao grupo escolar de $5^{\mathrm{a}}$ a $8^{\mathrm{a}}$ séries ou do $6^{\circ}$ ao $9^{\circ}$ ano do Ensino Fundamental. Nos PCN, a nomenclatura para referir-se ao Fundamental I aparece como $1^{\circ}$ e $2^{\circ}$ ciclos e para o Fundamental II, $3^{\circ}$ e $4^{\circ}$ ciclos.

${ }^{3}$ Serafini (1998) explica que alguns gêneros, por serem mais simples, requerem dos alunos capacidades que se desenvolvem em idade anterior àquela que se desenvolve para a escritura de gêneros mais complexos como o artigo de opinião.
} 
A experiência ${ }^{4}$ com alunos dos anos finais do EF I, em escolas públicas de periferia, tem nos mostrado que, nesse nível de ensino, os alunos são menos autônomos, se compararmos aos agrupamentos de alunos do EF II, isto é, do $6^{\circ}$ ano $9^{\circ}$ ano do Ensino Fundamental. Por isso, quanto mais próximo o professor puder intervir e acompanhar a revisão de texto do aluno, mais produtiva lhe será tal tarefa.

Partindo, então, de um trabalho processual e do ensino por meio dos gêneros, podemos distinguir dois tipos de correções: a correção oral coletiva e a correção escrita individual. A análise linguística coletiva ocorre quando o professor seleciona a produção textual de um aluno e a escreve no quadro, papel pardo ou faz uso de qualquer outro suporte para apresentar o tex to de um aluno, com a sua permissão, aos demais, tal como o aluno o produziu. O professor escreve o texto, corrigindo-o, alterando expressões, incluindo informações quando algo estiver vago, eliminando repetições, incluindo pontuações, acentuações, organizando parágrafos, estabelecendo os laços coesivos, revendo a ortografia, substituindo uma linguagem por outra etc.

É nessa situação de análise linguística de revisão coletiva de um tex to que o aluno poderá aprender normas de questões simples como: "Inicie uma frase com letra maiúscula", "Empregue um ponto ao final das orações". E questões mais amplas como especificidades das situações comunicativas: "Será que podemos usar essa linguagem para falar com o diretor da escola?" "Que palavra fica melhor para dizer isso?”.

Dessa forma, as análises linguísticas, além de auxiliarem os alunos em suas revisões de texto, exercem o papel de ensino de inúmeras questões que não se restringem ao emprego normativo de alguma regra ou questões superficiais, por exemplo, de ortografia. Elas contemplam esse viés necessário, porém, abrindo espaço para abordagem de questões textuais mais profundas como a coerência textual e as características dos gêneros estudados.

Quanto à correção escrita individual, consiste nas anotações que o professor faz no (e sobre o) texto do aluno. Ruiz (2010), retomando Serafini (1998), discorre acerca de correções resolutivas, indicativas e classificatórias, acrescentando a importância dos bilhetes escritos pelo professor.

No entanto, é preciso perceber tais orientações à luz de um novo público-alvo, não mais alunos do $9^{\circ}$ ano do EF II com que as autoras trabalharam, mas alunos que se iniciam na escrita de textos.

De acordo com os conceitos já discutidos, as correções resolutivas ofereceriam uma resposta pronta ao aluno. $\mathrm{O}$ aluno não refletiria sobre a natureza de seus erros, mas tal estratégia o conduziria a substituir uma forma inadequada por uma forma adequada, resolvendo de imediato o problema de seu texto. Ademais, auxiliaria o aluno a desenvolver o hábito de revisar. Ou seja, o aluno acostumar-se-ia com o processo de receber seu próprio tex to com notificações a serem consideradas.

As correções indicativas pouco auxiliariam o aluno na tarefa de revisar seu texto, pois, considerando que são alunos iniciantes na atividade de produção textual, indicar o erro com um traço sob a palavra em uma frase somente seria produtivo se houvesse a certeza de que o aluno já dispõe de conhecimento prévio para conseguir associar uma indicação a esse conhecimento disponível. Para exemplificar: se o professor já discutiu inúmeras vezes que em início de frases deve-se empregar a inicial maiúscula e combinar com seus alunos que indicará com um traço onde é preciso corrigir algo, é possível que alguns alunos consigam recordar-se da regra. Ao contrário, se essa regra foi poucas vezes mencionada, pouco sentido fará um traço embaixo de uma palavra para indicar que a letra inicial deve ser maiúscula.

Por sua vez, as correções classificatórias compartilham da mesma justificativa das correções indicativas. Elas requerem do aluno certo conhecimento prévio que, nesse caso, constrói-se privilegiadamente com algum tempo de estudo no ambiente escolar. Ou seja, classificar a natureza de um erro para o aluno depende do conhecimento que ele já tem para compreender o significado dessa natureza, fato menos recorrente nesses anos de escolaridade, principalmente, por estarem em início desse processo de construção. Por exemplo, as letras $\mathrm{CN}, \mathrm{CV}, \mathrm{P}$ fariam pouco sentido na frase: Os menino estava no parque.

\footnotetext{
${ }^{4}$ Há dez anos temos trabalhado com grupos de alunos do EF I e, entre sucessos e insucessos na sala de aula, temos observado algumas formas produtivas de trabalho.
} 
Dessa forma, entende-se que, para alunos em estudos iniciais, classificar a origem do problema demandaria que já tivessem estudado e compreendido o que significa $\mathrm{CN}$ - concordância nominal, $\mathrm{CV}$ - concordância verbal - e P - pontuação. Acredita-se, então, que estas sejam estratégias menos produtivas.

Tendo em vista que o público-alvo das correções são crianças com cerca de nove, dez e onze anos de idade, inserir algo que se aproxime do lúdico pode ser uma forma eficaz de produzir uma correção a distância, isto é, uma correção escrita.

Adaptando a correção resolutiva de Serafini (1998), propomos que o professor estabeleça com sua turma alguns códigos e mantenha expostos em sua sala de aula os significados de tais códigos. Por exemplo, poderiam combinar que uma estrelinha no texto indicaria o uso de um acento agudo; uma bolinha, o uso de iniciais maiúsculas; uma lua, o uso de vírgula; um sol, o uso do 's' indicativo de plural etc. Dessa forma, os alunos começariam a se apropriar gradativamente desta linguagem - maiúscula, plural, vírgula, ponto e vírgula, entre outros -, diferenciando, inclusive, um termo de outro, como em acento agudo e acento circunflexo, sem reduzir o valor da nomenclatura, como se vê nos apelidos dados ("grampinho e chapeuzinho") para denominar os acentos indicativos de sons abertos e fechados.

\section{CONCLUSÃO}

Este estudo nos fez refletir sobre duas questões: De que forma o professor tem realizado as devolutivas das redações corrigidas ao aluno? $\mathrm{O}$ que nos dizem os estudiosos da área quanto aos processos de avaliação/correção do texto escrito do aluno?

Essas questões de ensino-aprendizagem de produção escrita têm sido bastante exploradas nos últimos tempos. Sobre elas, é recorrente, na literatura mais atual sobre o tema, a indicação de se perceber o ensino da produção textual como um trabalho processual e não como mera escrita de um texto sem objetivo, como atividade isolada, que permanece na primeira versão feita pelo aluno com a nota da primeira e única correção do professor. De acordo com essa escrita isolada, percebe-se o quão desastroso tem sido o ensino das produções escritas: temas artificiais, propostas descontextualizadas e distantes da vivência do aluno.

Ao tentarmos apresentar uma solução para esse problema, apontou-se brevemente um direcionamento para contextualizar as propostas desse ensino e, assim, aproximá-las da vivência do aluno. Apontou-se, também, como ponto de partida, o ensino da produção textual por meio do ensino de gêneros, ou seja, não um texto sem identidade, sem face, mas um texto com características próprias e com uma linguagem que precisa adequar-se ao contexto de comunicação específico, às suas condições de produção.

Diante dos objetivos propostos neste trabalho, apresentamos uma reflexão sobre o que nos dizem os estudiosos da área a respeito dos processos de correção do texto escrito do aluno. Ao tentarmos ampliar nossos objetivos, percebendo a necessidade de se oferecer uma alternativa, que se quis produtiva para a atuação do professor, isto é, as considerações sobre a análise linguística coletiva e correção escrita individual, procuramos despertar o interesse pela continuidade desta pesquisa para que possa resultar na divulgação de estratégias de correção e, assim, contribuir para o trabalho dos professores do Ensino Fundamental I.

Dessa forma, preocupamo-nos em destacar uma das finalidades do ensino de Língua Portuguesa, isto é, o desenvolvimento da competência escritora dos estudantes e, assim, as estratégias de correção relevantes para o trabalho de conduzir o aluno a evoluir em sua produção escrita.

\section{REFERÊNCIAS}

ANTUNES, I. Aula de português: encontro \& interação. São Paulo: Parábola, 2006.

Lingua, texto e ensino: outra escola possível. 2. ed. São Paulo: Parábola, 2009.

BAKHTIN, M. Estética da criação verbal. São Paulo: Martins Fontes, 1992.

BAZERMAN, C. Gênero, agência e escrita. Tradução de Judith C. Hoffnagel. São Paulo: Cortez, 2006. 
BUNZEN, C. Da era da composição à era dos gêneros: o ensino de produção de texto no ensino médio. In: ; MENDONÇA, Márcia. (Orgs.). Português no ensino médio e formação do professor. São Paulo:

Parábola, 2006. p. 139-161.

COSTA, S. R. Dicionário de gêneros textuais. Belo Horizonte: Autêntica, 2008.

CRISTÓVÃO, V. L. L. Modelo didático de gênero como instrumento para a formação de professores. In: MEURER, J. L.; MOTTA-ROTH, D. (Org.). Gêneros textuais e práticas discursivas: subsídios para o ensino da linguagem. Bauru, SP: EDUSC, 2002. p. 31-73.

GAYDECZKA, B. As pesquisas a respeito de gêneros discursivos no Brasil e suas aplicações ao ensino. In: KARWOSKI, A. M.; BONI, V. F. C. (Org.). Tendências Contemporâneas no ensino de línguas. União da Vitória, PR: Kaygangue, 2006. p. 84-103.

GERALDI, J. W. Unidades básicas do ensino de português. In: Paulo: Ática: 2007. p. 59-79.

(Org.). O texto na sala de aula. São

LOPES-ROSSI, M. A. G. O desenvolvimento de habilidades de leitura e de produção de textos a partir de gêneros discursivos. In: LOPES-ROSSI, M. A. G. (Org.). Gêneros discursivos no ensino da leitura e produção de textos. Taubaté, SP: Cabral, 2002. p. 19-40.

. Práticas de produção de gêneros discursivos no ensino de língua portuguesa. In: KARWOSKI, A. M.; BONI, V. F. C. (Org.). Tendências Contemporâneas no ensino de línguas. União da Vitória: Kaygangue, 2006. p. 67-77.

. A produção escrita de gêneros discursivos em sala de aula: aspectos teóricos e sequência didática.

Taubaté: Universidade de Taubaté, 2012. (Não Publicado).

MARCUSCHI, L. A. Produção textual, análise de gêneros e compreensão. 2. ed. São Paulo: Parábola, 2008.

MENDONÇA, M. Análise linguística no ensino médio: um novo olhar, um outro objeto. In: BUNZEN, C.; MENDONÇA, M. (Org.). Português no ensino médio e formação do professor. 3. ed. São Paulo: Parábola, 2009. p. 199-226.

MEURER, J. L.; MOTTA-ROTH, D. (Orgs.). Gêneros textuais. Bauru, SP: EDUSC, 2002.

PASSARELLI, L.G. Ensinando a escrita: o processual e o lúdico. 4. ed. rev. e ampl. São Paulo: Cortez, 2004.

Domínio discursivo jurídico: procedimentos argumentativos no gênero textual decisão

interlocutória. In: CORREA, L. (Org.). Direito e argumentação. Barueri, SP: Manole, 2008a. p. 116-137.

. Educação linguística articulando teoria e prática: relações sintagmáticas anafóricas e catafóricas no

plano do texto. In: CINTRA, A. M. M. (Org.). Ensino de Lingua Portuguesa: reflexão e ação. São Paulo: EDUC, 2008b. p. 75-94.

RUIZ, E. Como corrigir redações na escola. São Paulo: Contexto, 2010.

SERAFINI, M. T. Como escrever textos. 9. ed. São Paulo: Globo, 1998.

Recebido em 20/03/13. Aprovado em 30/06/13. 